\section{Adoption of Plug-in Hybrid Electric Vehicle among Malaysian Consumers}

Nadia Adnan ${ }^{1}$, Pandian M Vasant ${ }^{2^{*}}$, Imran Rahman ${ }^{3}$ and Amir Noor ${ }^{3}$

${ }^{1}$ Department of Management and Humanities, Universiti Teknologi PETRONAS, Bandar Seri Iskandar, Perak, Malaysia

${ }^{2}$ Department of Fundamental and Applied Sciences, Universiti Teknologi PETRONAS, Bandar Seri Iskandar, Perak, Malaysia

${ }^{3}$ Department of Computer Science, London Metropolitan University, 166-220 Holloway Rd, Holloway, London N7 8DB, UK

*Corresponding author: Vasant PM, Department of Fundamental and Applied Sciences, Universiti Teknologi PETRONAS, Bandar Seri Iskandar, Perak, Malaysia, Tel: +60 169101486; E-mail: pvasant@gmail.com

Received date: March 29, 2016 Accepted date: May 25, 2016, Published date: June 02, 2016

Copyright: (C) 2016 Adnan N, et al. This is an open-access article distributed under the terms of the Creative Commons Attribution License, which permits unrestricted use, distribution, and reproduction in any medium, provided the original author and source are credited.

\section{Short Communication}

Recent day transportation sectors are leading in the direction of revolution for attaining sustainability and reduce the effect of $\mathrm{CO}_{2}$ emission. Although road transportation is not considered the foremost the only source of greenhouse-gas emissions, but it is a debatable topic. Traditional transport is a key source of unsustainable energy use, depends on the liquid fossil fuels. Research suggests that the transportation sector at present consume over $55 \%$ of oil and emit around $25 \%$ of $\mathrm{CO}_{2}$ in total [1]. With the introduction of electric vehicles technology marked a considerable amount of carbon-free transportation in a current market trend [2]. By keeping a close consideration at the research on electric vehicle technology adoption, the main idea was to incorporate electrically charged battery supported vehicles i.e. PHEVs came into the current market trend [3]. We scale out our domain to study their potential introduction from an integrated perspective of PHEVs. Further, we extend our domain to observe its interactions between technology and behavior and its market diffusion influence [4]. In the context of this study, environmental concerns were defined as the degree to which Malaysian consumers are aware of problems regarding the environment and support the effort to solve them or indicate the willingness to contribute personally to the solution. Therefore, Figure 1 illustrates the vehicles electrification comparison range such as: the vehicles operate as an off-grid (or conventional) hybrid, with the fuel economy benefits that result from relying on the battery and electric motor to reduce efficiency losses. Nonetheless, the plug-in hybrid electric vehicles involved in producing more power from the battery than conventional hybrids vehicles because they completely depend on the electricity from their on-board battery.

\section{Plug-in Hybrid Electric Vehicles (PHEVs)}

Plug-in hybrid electric vehicles is a vehicle which is proficient of running together by the help of two different power systems based on grid-supplied electricity stored in an on-board battery and refined liquid fuels in an Internal combustion engine (ICE). However, the current era of hybrid vehicles such as Toyota Prius is different from PHEVs, because the plug-in hybrid electric vehicles completely powered by battery over a particular distance which can be reenergized from the electric grid. Elsewhere this particular distance, or "all-electric range," the vehicles operate as an off-grid (or conventional) hybrid, with the fuel economy benefits that result from relying on the battery and electric motor to reduce efficiency losses. Figure 2 shows PHEVs' advanced electricity utilization where we can see the different way of electricity usage [5].

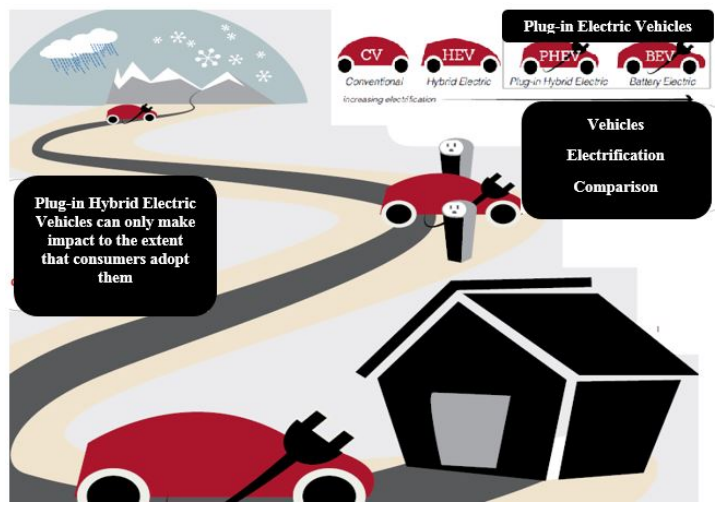

Figure 1: Vehicles electrification comparison.

\section{Key Factors of Malaysian Consumer Incentives toward PHEVs Adoption}

Public acceptance and diffusion of PHEVs are relatively fresh and unfamiliar issues in the most of the developing countries such as Malaysia. In fact, public acceptance can appear as a prevailing obstacle for market diffusion and impede the development of technology adoption [6]. However, the consumer preferences are diverse in a developing country that is the reason why the formulation of marketing strategies will address the real want and needs of future electric consumers.

\section{Malaysian consumer preferences}

In the line of this research study, we found that conventional consumers in developing countries such as Malaysia are ready to adopt PHEVs at the same cost or equivalent to that of gasoline vehicles only if its value reduces up to an average of $\$ 10,000$ to $\$ 20,000$ in general. In comparison, developed countries are more ready to purchase PHEVs if they have multiple ranges of vehicles available. However at the mainstream level, both developing and developed countries consumers show their interest towards the adoption of PHEVs. Nevertheless, developing countries such as Malaysian market are more in growing stage because of the Malaysian government policy on Green Tech 2010. It is also mentioned in the report that, in order to promote sustainable economy, one solution is to switch from gasoline-based vehicles to green technology vehicles. Whereas, adoption of PHEVs gives greener and cleaner vehicles, which is supported by Malaysian government. 


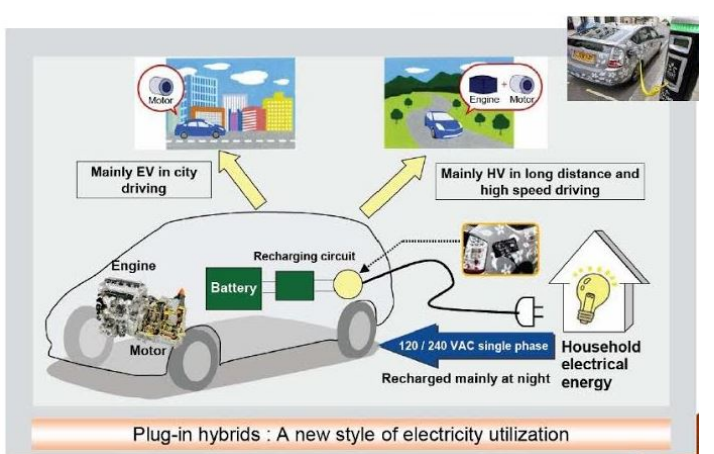

Figure 2: Plug-in HEVs Source: www.toyota.com.

\section{Policy}

Under federal fuel economy standards, Malaysian government mandates electric vehicle sales allow different metropolises in Malaysia which support them towards the adaptation of large-emitting vehicle fleets. The result will be greater division in the types of vehicles bought in other countries without minimizing emissions or consumption of gasoline. Proper management can ensure loss minimization of the grid and enhance the transmission and generation of electric power supply [7]. The control of PHEVs charging depending on the locations can be classified into two groups; household charging and public charging. Recent researches focus on the public charging station for plug-in vehicles because most of PHEVs charging is expected to take place in public charging location. The policymakers would essence on the more suitable intervention and policy to encourage the development of electric vehicles as a part of the strategy towards an evolution to a low carbon society in Malaysia.

\section{Cost}

The biggest economic obstacle towards the adoption of the electric vehicle in Malaysia is the battery cost of PHEVs [8]. Large battery manufacturing factories can make sure to cut-off the cost slightly, but we calculate that the saving of cost with respect to high-volume manufacturing are almost fatigued at the production volumes.

\section{Implications}

There is an inordinate expectation towards the adoption of plug-in hybrid electric vehicles that would play a significant part in energy infrastructure to empower societies globally as an energy system to reduce $\mathrm{CO}_{2}$ for future generation. However, few developed nations have already replaced a portion on plug-in hybrid electric vehicles in their economy. Importantly, numerous progressive developing nations as well as Malaysia are also viewing in this way and recently introduces several types of research and technological innovations. While the benefits of prioritizing a modern innovation gives emission-free future electric vehicle transport system. Therefore, there are a big issues raised on how a national economy can deliberate and implement such policy options which for the policy makers and the consumer. Generally, the knowledge generated over the last decade has not given the clear picture towards the adoption of plug-in hybrid electric vehicles $[9,10]$. According to a statistics of Electric Power Research Institute (EPRI), most of the Malaysian vehicle will comprise of PHEVs within the next few decades [11]. To make Malaysian consumer aware towards the adoption of electric vehicles is the major concern among policymakers. This study considers those raised issues with an awareness of PHEVs by looking at the consumer preferences and environmental knowledge with sustainable environmental care for future generation.

\section{Conclusions and Future Work}

Keeping the facts in consideration that genuinely affect adoption behavior of electrified vehicles are: Findings of Green technology policy 2009 and national automatic policy 2014 should be referred as the spine policies to allow this sector to quicken and transmute the automotive industry to be one of the vital contributors for the national economy. Report heighted that Malaysian consumers require cost effective approach along with reliability, increasing in production volume would not set an exemplary market gets limited residential parking which poses a direct long-term limitation to mainstream adoption. Investment in Public charger is an expensive approach to saving petroleum fuel. Normal or extreme weather are the key factor of regional adaptation and are a proportional threat in case of loss of vehicle in extreme conditions. The policy maker's offers the guideline for the formulation of marketing strategies that will address the real needs and wants for future electric vehicles users in Malaysia. The government and policy maker should take a serious action towards the implication of electric vehicles in Malaysia as part of the strategy to increase energy efficiency, reduce emissions and reduce the reliance on fossil fuels within the transportation sector. Yet, there is a dire need for consumer awareness and education on the issue of climate change and energy effectiveness. However, it an absolutely benefit to elevate the consumer knowledge level which will influence the level of acceptance towards the plug-in hybrid electric vehicles.

\section{References}

1. Tuttle DP, Kockelman KM (2012) Electrified vehicle technology trends, infrastructure implications, and cost comparisons. Journal of the Transportation Research Forum 51: 35-51.

2. Rahman I, Vasant PM, Singh BSM, Abdullah-Al-Wadud M, et al. (2016) Review of recent trends in optimization techniques for plug-in hybrid, and electric vehicle charging infrastructures. Renewable and Sustainable Energy Reviews 58: 1039-1047.

3. Schuitema G, Anable J, Skippon S, Kinnear N (2013) The role of instrumental, hedonic and symbolic attributes in the intention to adopt electric vehicles, Transportation Research Part A: Policy and Practice 48: 39-49.

4. Egbue O, Long S (2012) Barriers to widespread adoption of electric vehicles: An analysis of consumer attitudes and perceptions. Energy policy 48: 717-729.

5. Hu X, Murgovski N, Johannesson L, Egardt B (2013) Energy efficiency analysis of a series plug-in hybrid electric bus with different energy management strategies and battery sizes. Applied Energy 111: 1001-1009.

6. Hu X, Moura SJ, Murgovski N, Egardt B, Cao D (2016) Integrated Optimization of Battery Sizing, Charging, and Power Management in Plug-In Hybrid Electric Vehicles. IEEE Transactions on Control Systems Technology 24: 1036-1043.

7. Hu X, Martinez CM, Yang Y (2016) Charging, power management, and battery degradation mitigation in plug-in hybrid electric vehicles: A unified cost-optimal approach. Mechanical Systems and Signal Processing.

8. Tran M, Banister D, Bishop JD, McCulloch MD (2012) Realizing the electric-vehicle revolution. Nature climate change 2: 328-333. 
Citation: Adnan N, Vasant PM, Rahman I, Noor A (2016) Adoption of Plug-in Hybrid Electric Vehicle among Malaysian Consumers. Ind Eng Manage 5: 185. doi:10.4172/2169-0316.1000185

Page 3 of 3

9. Zhang Q, Tezuka T, Ishihara KN, Mclellan BC (2012) Integration of PV power into future low-carbon smart electricity systems with EV and HP in Kansai Area, Japan. Renewable Energy 44: 99-108.

10. Amini MH, Jamei M, Lashway CR, Sarwat AI, Yen KK, et al. (2015) Plugin electric vehicle owner behaviour study using fuzzy systems International Journal of Power and Energy Systems 35.
11. Sang YN, Bekhet HA (2015) Modelling electric vehicle usage intentions: an empirical study in Malaysia. Journal of Cleaner Production 92: 75-83. 